\title{
INDUÇĀO DE ANTICORPOS ESPECÍFICOS PELA VACINA ANTI-SARAMPO ESTUDO EM CRIANÇAS NUTRIDAS E DESNUTRIDAS DE 6 a 24 meses
}

Gliane M. Cesário Pereira MaLUf (1), Raul Corrêa RIBELRo (2), Miguel Angel Lino RodriguEZ (3), Irene SKraba (4) e José Ferreira de Garvalho (5)

\section{R E S U M O}

Foi estudada a indução de anticorpos anti-sarampo em 223 crianças nutridas e desnutridas vacinadas entre 6 e 24 meses e naquelas que permaneceram soronegativas com 1 dose da vacina realizada antes dos 12 meses que foram revacinadas após os 12 meses. A determinação de anticorpos anti-sarampo foi realizada pelas técnicas de inibição da hemaglutinação e de soroneutralização. Observamos que a taxa de soroconversão aumentou progressivamente com a idade, sendo de $43 \%$ aos 6 meses e de $80 \%$ aos 15 meses. A taxa de soroconversão em crianças marasmáticas foì semelhante à obtida em crianças nutridas, concordando com a literatura que vem demonstrando que crianças desnutridas não apresentam alteração na capacidade de resposta humoral à vacina. Utilizando os dados de mortalidade por sarampo e as taxas de soroconversão à vacina, idealizou-se um modelo hipotético para a avaliação da aplicação da vacina em diferentes idades e suas consequiuências em têrmos de mortalidade, e observou-se que quando a vacina é realizada em idadesi precoces (67 meses) o número de óbito esperado é inferior ao esperado quando a vacina é realizada em idades posteriores (9-11 meses), indicando que a proposta atual do Ministério da Saúde de aplicar dose única aos 9 meses, teoricamente aumentaria o risco de mortalidade. Considerando o número de crianças protegidas com 1 dose de vacina aplicada antes dos 12 meses e o número de crianças protegidas com a revacinação a taxa de soroconversão foi de $84,3 \%$.

\section{N T ROD U G Ã O}

O sarampo é ainda uma importante causa de mortalidade infantil nos países em desen. volvimento. No Estado do Paraná, apesar dos registros oficiais informarem que a cobertura vacinal está próxima a $100 \%{ }^{14}$, o coeficiente de incidência da doença permanece elevado, alcançando níveis epidêmicos no ano de 1983. "Este fato indica que os programas de vacinação não têm conseguido imunizar grande parte das crianças vacinadas. A Fig. I mostra os índices de morbi-mortalidade por sarampo no Estado do Paraná.

Como os resultados finais da vacinação em massa dependem de vários fatores, incluindo-se entre os principais a qualidade de vacina aplicada e as condições de resposta do vacinado, achamos importante estudar os fatores que pudessem estar associados à baixa eficácia da va. cina em nossa comunidade; portanto, foram objetivos desse estudo: 1) Avaliar a taxa de so.

(1) Mestranda do Departamento de Pediatria do Hospital de Clinicas. Universidade Federal do Paraná, Curitiba, PR, Brasil

(2) Professor-assistente do Departamento de Pediatria do Hospital de Clínicas. Universidade Federal do Paranḱ

(3) e (4) Técnicos do Laboratório de Pesquisas Biológicas da Secretaria de Saúde e Bem-Estar Social do Estado do Paraná

(5) Professor Livre-docente do IMECC - UNICAMP 
MALUF, E. M. C. P.; RIBEIRO, R. C.; RODRIGUUE, M. A. L.; SKRABA, I. \& CARVALHO, J. F. de - Indução de anti. corpos especfficos pela vacina anti-sarampo. Estudo em crianças nutriđas e desnutridas de 6 a 24 meses. Rev. Inst. Med. trop. São Paulo 27:353-360, 1985.

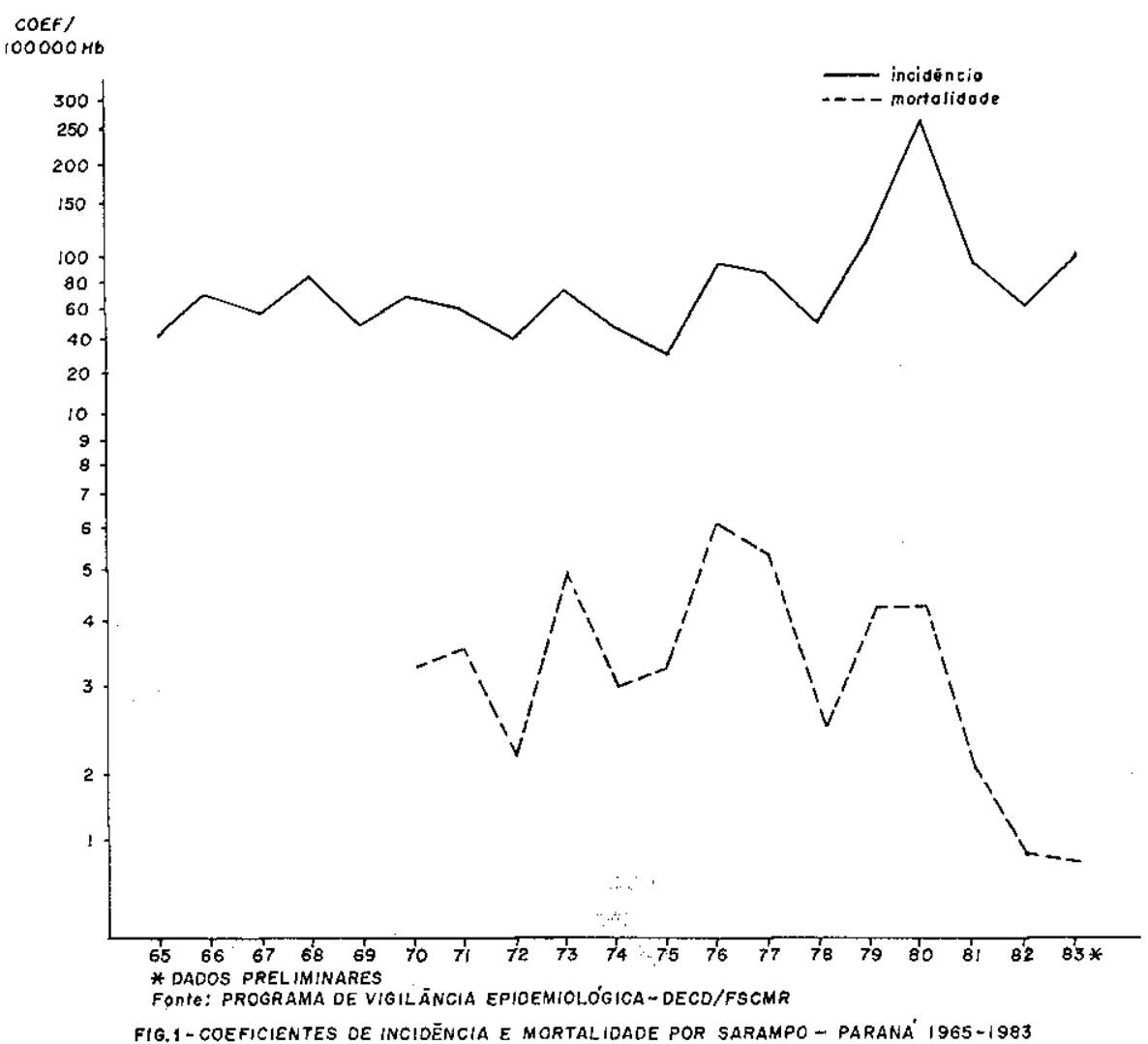

SESB/GPS-06/84

roconversão obtida em crianças vacinadas con tra o sarampo entre 6 e 24 meses em nossa comunidade; 2) Avaliar se os fatores sexo, es. tado nutricional e idade à vacinação, podem in fluenciar na taxa de soroconversão obtida; 3) Avaliar as principais alternativas para um es. quema de vacinação contra o sarampo em termos de suas consequiências epidemiológicas.

\section{CASUISTICA E METODOLOGIA}

Foram incluídas no estudo crianças de 6 a 24 meses que não haviam recebido a vacina anti-sarampo (comprovado pela carteira de vacina).

Foram excluídas crianças com história anterior de sarampo, manifestação de doença aguda, sob tratamento imunossupressor, história de prematuridade, que haviam recebido sangue, plasma ou imunoglobulina até 6 semanas antes ou após a vacinação, e que apresentavam título de anticorpos anti-sarampo na amostra colhida pré-vacinação considerado protetor.
A casuística foi composta por 223 crianças, sendo $108(48,4 \%)$ do sexo masculino e 115 $(51,6 \%)$ do feminino. Dessas, 201 eram crian. ças nutridas e 22 desnutridas. Foram classificadas como desnutridas aquelas que apresen. tavam peso abaixo do $2 .^{\circ}$ desvio padrão negativo pela tabela de desenvolvimento pondo estatural de Marcondes, correspondente à classe IV de Santo André. Esses desnutridos foram caracterizados pelos critérios clínico - laboratoriais de MCLAREN ${ }^{10}$ e considerados $\mathrm{Ma}$ rasmáticos.

Posteriormente, 94 crianças que permanece ram soronegativas após a vacinação realizada antes dos 12 meses foram solicitadas para a revacinação. Dessas, 27 retornaram e foram revacinadas e submetidas à avaliação sorológi ca.

As amostras de sangue foram colhidas em discos de papel de filtro por punção digital: $O$ intervalo para a coleta de amostras pré e pós 
MALUF, E. M. C. P.; RIBEIRO, R. C.; RODRIGUEZ, M. A. L.; SKRABA, I. \& CARVALAZO, J. F. de - Indução de anti. corpos especificos pela vacina anti-sarampo. Estudo em crianças nutridas e desnutridas de 6 a 24 meses. Rev. Inst. Med. trop. Săo Paulo 27:353-360, 1985.

vacinação foi de 4 semanas. A determinação dos títulos de anticorpos anti-sarampo foi realizada pela técnica de inibição da hemaglutinação e considerou-se como positivo um título $\equiv 1: 10$ Para controle de qualidade, parte das amostras foi submetida a avaliação pela técnica de soroneutralização, e considerou-se como positivo título $\supseteq 1: 5$.

Os lotes das vacinas utilizadas no estudo foram submetidos à determinação da potência e verificou-se que todos continham pelo menos $1000 \mathrm{TCDI}_{50} /$ dose, isto é, estavam dentro dos pa. drões exigidos.

\section{RESULTADOS}

\section{Comparação entre os resultados obridos pelas técnicas de inibição da hemaglutinação e soroneutralização}

A comparação entre os títulos de anticorpos obtidos com as duas técnicas é apresentada na Tabela $I$. Observamos que quando os títulos são negativos para a técnica de inibição

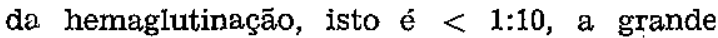
maioria também é negativa para a técnica de soroneutralização. Entretanto, quando os títulos são positivos para a técnica de inibição da hemaglutinação, não há uma relação matema. ticamente bem determinada entre os títulos positivos obtidos pela soroneutralização.

T A B E I A I

Comparação entre os títulos obtidos com 289 amostras submetidas aos testes de inibiçä́ da hemaglutinaçăo e soroneutralizaçăo

\begin{tabular}{crrrrrrrr}
\hline & \multicolumn{7}{c}{ HI } \\
NT & $<1: 10$ & $1: 10$ & $1: 20$ & $1: 40$ & $1: 80$ & $1: 160$ & $1: 320$ & Total \\
\hline$<1: 5$ & 176 & 2 & - & - & - & - & - & 178 \\
$1: 5$ & 4 & 6 & 2 & - & - & - & - & 12 \\
$1: 7,5$ & 10 & 1 & - & 1 & - & - & - & 12 \\
$1: 10$ & 3 & 5 & 2 & - & 1 & - & - & 11 \\
$1: 15$ & 3 & 8 & 3 & - & - & - & - & 14 \\
$1: 20$ & 1 & 4 & 4 & 1 & - & - & - & 10 \\
$1: 30$ & 2 & 4 & 5 & 3 & - & - & - & 14 \\
$1: 40$ & - & 1 & 5 & 3 & 1 & - & - & 10 \\
$>1: 60$ & - & 2 & 7 & 12 & 5 & 1 & 1 & 28 \\
\hline Total & 199 & 33 & 28 & 20 & 7 & 1 & 1 & 289 \\
\hline
\end{tabular}

Como o que nos interessa era saber se os títulos eram positivos ou negativos comparamos esses resultados obtidos com as duas técnicas os quais são apresentados na Tabela II. Dessa forma obtivemos que a sensibilidade da técnica de inibição da hemaglutinação foi de $88 \%$ e a especificidade de $98 \%$, tendo como referência a técnica de soroneutralizaçäo.

T A B E L A II

Comparaçāo entre os resultados obtidos com 289 amostras submetidas aos testes de inibiçāo da hemaglutinação e soroneutralização

\begin{tabular}{lcc}
\hline & \multicolumn{2}{c}{ HI } \\
\cline { 2 - 3 } NT & $\begin{array}{l}\text { Negativo } \\
(<1: 10)\end{array}$ & $\begin{array}{r}\text { Positivo } \\
(\equiv 1: 10)\end{array}$ \\
\hline $\begin{array}{l}\text { Negativo } \\
\begin{array}{l}(<1: 5) \\
\text { Positivo } \\
(\geq 1: 5)\end{array}\end{array}$ & 176 & 2 \\
\hline
\end{tabular}

\section{Avaliação da resposta à vacina}

As variáveis sexo, estado nutricional e idade à vacinação foram analisadas por um mo. delo de regressão logística para determinar a relação com a soroconversão à vacina. Os resultados mostraram que apenas a idade à var cinação influenciou a soroconversão à vacina. O sexo e o estado nutricional não tiveram qualquer influência na taxa de soroconversão.

De fato, pode se observar na Tabela III que a taxa de soroconversão é inclusive mais alta no grupo de crianças desnutridas, embora essa diferença não seja estatisticamente significa. tiva.

T A B E I A III Comparaçāo entre a taxa de soroconversão obtida no grupo de crianças nutridas $\theta$ aquela obtida no grupo de crianças desnutridas

\begin{tabular}{lccc}
\hline & $\begin{array}{c}\text { Total de } \\
\text { crianças }\end{array}$ & $\begin{array}{r}\text { N.o de crlanças } \\
\text { com soroconversăo }\end{array}$ & $\begin{array}{c}\text { Porcentagem de } \\
\text { crianças com } \\
\text { soroconversāo }\end{array}$ \\
\hline Nutridạs: & 201 & 115 & 57,2 \\
Desnutridas & 22 & 14 & 63,6 \\
\hline Total & 223 & 129 & 57,8 \\
\hline
\end{tabular}

A Tabela IV mostra a distribuição por faixa etária dos títulos de anticorpos anti-sarampo encontrađos pós-vacinação. Observam-se que das 223 amostras estudadas, 94 (42,1\%) permaneceram com titulos de anticorpos antisarampo $<1: 10$, considerados negativos. 
MALuf, E. M. C. P.; RIBEIRO, R. C.; RODRIGUEz, M. A. L.; SKRABA, I. \& CARVALHO, J. F. de - Indução de anti. corpos especificos pela vacina anti-sarampo. Estudo em crianças nutridas e desnutridas de 6 a 24 meses. Rev. Inst. Med. trop. São Paulo 27:353-360, 1985.

T A B E L A IV

Distribuição por faixa etária dos títulos de anticorpos anti-sarampo pós vacinaçäo

\begin{tabular}{crrrrrrr}
\hline & \multicolumn{7}{c}{ Idade em meses } \\
\cline { 2 - 7 } $\begin{array}{c}\text { Titulos de } \\
\text { anticorpos } \\
\text { (HI) }\end{array}$ & 6 & 7 & 8 & 9 & $10-11$ & $12-24$ \\
\hline$<1: 10$ & 1 & 56 & 10 & 13 & 6 & 8 \\
$1: 10$ & 3 & 16 & 8 & 3 & 9 & 4 \\
$1: 20$ & - & 11 & 6 & 2 & 5 & 9 \\
$1: 40$ & - & 9 & 5 & 5 & 5 & 14 \\
$1: 80$ & - & 6 & 1 & 3 & - & 1 \\
$1: 160$ & - & - & 1 & - & 1 & - \\
$1: 320$ & - & 1 & - & 1 & - & - \\
\hline Total & 4 & 99 & 31 & 27 & 26 & 36 \\
\hline
\end{tabular}

A avaliação da porcentagem de soroconversão para cada faixa etária é apresentada na Tabela $V$. Observa-se que houve tendência a um aumento progressivo na taxa de soroconversão som o aumento da idade, entretanto observase uma flutuação nesses resultados que podem ser considerados imprecisos devido ao pequeno número de crianças contido em algumas faixas etárias. Esses resultados foram ajustados pelo método da verossimilhança e dessa forma verificou-se um aumento progressivo na taxa de soroconversão com o aumento de idade.

T A B E L A V

Comparaçâo entre os valores da porcentagem de soroconversão ajustados e estimados diretamente nas diferentes faixas etárias

\begin{tabular}{lrrrrrrrrrrr}
\hline $\begin{array}{l}\text { Idade } \\
\text { (meses) }\end{array}$ & 06 & 07 & 08. & 09 & 10 & 11 & 12 & 13 & 14 & 15 \\
\hline Ajustado $(\%)$ & 43 & 47 & 52 & 57 & 51 & 65 & 69 & 73 & 77 & 80 \\
Direto & $(\%)$ & 25 & 43 & 65 & 52 & 80 & 75 & 70 & 67 & 86 & 1.00 \\
$N$ & & 4 & 99 & 31 & 27 & 10 & 16 & 10 & 3 & 7 & 2 \\
\hline
\end{tabular}

As crianças que permaneceram soronegativas com I dose de vacina aplicada antes dos 12 meses foram revacinadas após essa idade. $O$ intervalo minimo entre $1 .^{\circ}$ e $2 .^{\circ}$ dose foi de 6 meses. Esse grupo fol constituído por 27 crianças e os resultados da revacinação estão apresentados na Tabela VI.

Observa-se que mesmo com a revacinaçāo a porcentagem de crianças que não apresentou soroconversão é ainda $37,1 \%$.

A Tabela VII apresenta uma comparação entre a taxa de soroconversão obtida na revacinação em um grupo que recebeu a primeira
T A B E I A VI

Resultados da revacinação nas crianças que não apresentaram título de anticorpos anti-sarampo considerados protetores após terem recebido uma dose da vacina antes dos 12 meses

\begin{tabular}{cccc}
\hline $\begin{array}{c}\text { Idade da } \\
\text { revacinaçāo }\end{array}$ & $\begin{array}{c}\text { N.0 total de } \\
\text { crianças }\end{array}$ & $\begin{array}{c}\text { N.* de crianças } \\
\text { com soroconversão }\end{array}$ & $\begin{array}{c}\text { Porcentagem dè } \\
\text { crianças com } \\
\text { soroconversāo }\end{array}$ \\
\hline $13-18 \mathrm{~m}$ & 27 & 17 & 62,96 \\
\hline
\end{tabular}

dose da vacina entre 6 e 7 meses e, em outro grupo que recebeu a $1 .^{a}$ dose entre 8 e 10 meses. Observamos que as taxas de soroconversāo foram semelhantes nos dois grupos.

T A B E L A VIJ

Relação entre a idade em que foi realizada a primeira dose da vacina anti-sarampo e a resposta a segundi dose

\begin{tabular}{lrrr}
\hline Idade da & & \multicolumn{2}{c}{ Soroconversăo com a 2.a dose } \\
\cline { 3 - 4 } 1. a dose & N.० de crianças & N.0 & $(\%)$ \\
\hline $07 \mathrm{~m}$ & 19 & 12 & 63,15 \\
$08.10 \mathrm{~m}$ & 8 & 5 & 62,50 \\
\hline Total & 27 & 17 & 62,96 \\
\hline
\end{tabular}

Determinação da idade ótima para a vacinação anti-sarampo

Utilizando os dados de mortalidade por sarampo específicos por idade fornecidos pelo Ministério da Saúde para o Paraná no ano de 1979 (Tabela VIII) e as taxas de soroconversão obtidas nesse estudo, elaboramos um modelo teórico para verificar o efeito da vacinação em diferentes idades nas taxas de mortalidade.

Esse modelo utilizou o método de Coorte e baseou-se no acompanhamento de 100000 recém-nascidos durante seus 10 primeiros anos de vida. O número total de óbitos esperado para diferentes idades de realização da vacina foi o resultado da somatória dos óbitos esperados para as crianças suscetíveis em idades anteriores à aplicaçãa da vacina e a soma tória dos óbitos esperados para a população que permaneceu suscetível após a vacinação (Fig. 2).

Os resultados obtidos por esse modelo teó rico são apresentados na Tabela IX. Observamos que a mortalidade foi menor quando a vacina foi aplicada no sétimo mês e que essa aumenta progressivamente à medida que a vacina é aplicada em idades posteriores. 
MALUF, E. M. C. P; RIBEIRO, R. C.; RODRIGUEZ, M. A. L.; SKRABA, I. \& CARVALHO, J. F. de - InđuÇão de anticorpos especificos pela vacina anti-sarampo. Estuđo em crianças nutridas e desnutridas de 6 a 24 meses. Rev. Inst. Med. trop. São Paulo 27:353-360, 1985.

\section{TA B E L A VIII}

Distribuição por faixa etấria da taxa real dos óbitos e comparação com a taxa corrigida, caso a vacinação não tivesse sido realizada aos sete meses

Taxa corrigida $(*)$

Idade População obitos Taxa $\left(/ 10^{5}\right)$ (P/vacinaçāo aos $7 \mathrm{~m}$ )

\begin{tabular}{|c|c|c|c|c|c|}
\hline$<1 \mathrm{~m}$ & 19.528 & 1 & 5,1 & 5,1 & \\
\hline Im & 18.079 & 2 & 11,1 & 11,1 & . \\
\hline $2 \mathrm{~m}$ & 17.185 & 7 & 40,7 & 40,7 & \\
\hline $3 \mathrm{~m}$ & 18.211 & 4 & 22,0 & 22,0 & \\
\hline $4 \mathrm{~m}$ & 17.105 & 9 & 52,6 & 52,6 & $\because$ \\
\hline $5 m$ & 17.754 & 24 & 135,2 & 135,2 & \\
\hline $6 \mathrm{~m}$ & 15.253 & 23 & 141,5 & 141,5 & \\
\hline $7 \mathrm{~m}$ & 17.386 & 16 & 92,0 & 173,6 & \\
\hline $8 \mathrm{~m}$ & 18.770 & 18 & 95,9 & 180,9 & \\
\hline $9 m$ & 17.345 & 19 & 109,5 & 206,6 & \\
\hline $10 \mathrm{~m}$ & 18.352 & 13 & 70,8 & 133,6 & \\
\hline $21 m$ & 18.702 & 16 & 85,6 & 161,5 & \\
\hline $1 \mathrm{a}$ & 199.544 & 87 & 43,6 & 82,3 & \\
\hline $2 a$ & 206.072 & 44 & 21,4 & 40,4 & \\
\hline $3 a$ & 203.786 & 16 & 7,9 & 14,9 & \\
\hline $4 a$ & 201.757 & 4 & 2,0 & 3,8 & \\
\hline $5 a$ & 202.495 & 7 & 3,4 & 6,3 & \\
\hline $6 a$ & 196.347 & 6 & 3,1 & 5,8 & \\
\hline $7 \mathrm{a}$ & 198.527 & 3 & 1,5 & 2,8 & \\
\hline $8 a$ & 198.225 & 3 & 1,5 & 2,8 & \\
\hline $9 \mathbf{a}$ & 197.093 & - & - & 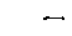 & \\
\hline $10 \mathrm{a}$ & 204.324 & 1 & 0,5 & 0,9 & \\
\hline$>10 a$ & (1) & 6 & $\ldots$ & $\cdots$ & \\
\hline
\end{tabular}

(1) Năo figuram nos cálculos

(2) Taxas a serem obtidas se nāo houvesse a vacinação aos sete meses

\section{T A B E L A IX}

Total de óbitos esperado para diferentes idades de realização da vacina

\begin{tabular}{cc}
\hline $\begin{array}{c}\text { Idade de vacinaçăo } \\
\text { (em meses) }\end{array}$ & Total esperado de obitos \\
\hline 06 & 934 \\
07 & 933 \\
08 & 1012 \\
09 & 1064 \\
10 & 1137 \\
11 & 1234
\end{tabular}

(1) em Coorte de 100000

\section{DISGUSSÃO}

As técnicas de inibição da hemaglutinação e de soroneutralização mostraram resultados comparáveis porém sem uma relação matematicamente bem definida entre esses. Devido a técnica de inibição da hemaglutinação ser de simples execução $3,4,6,9$, essa foi a técnica escolhida para a avaliação da resposta à vacina em nosso estudo.

A escolha de um determinado titulo de anticorpos a partir do qual se considera uma criança protegida contra o sarampo é até certo ponto arbitrária, visto que parece não haver correlação absoluta entre imunidade e níveis

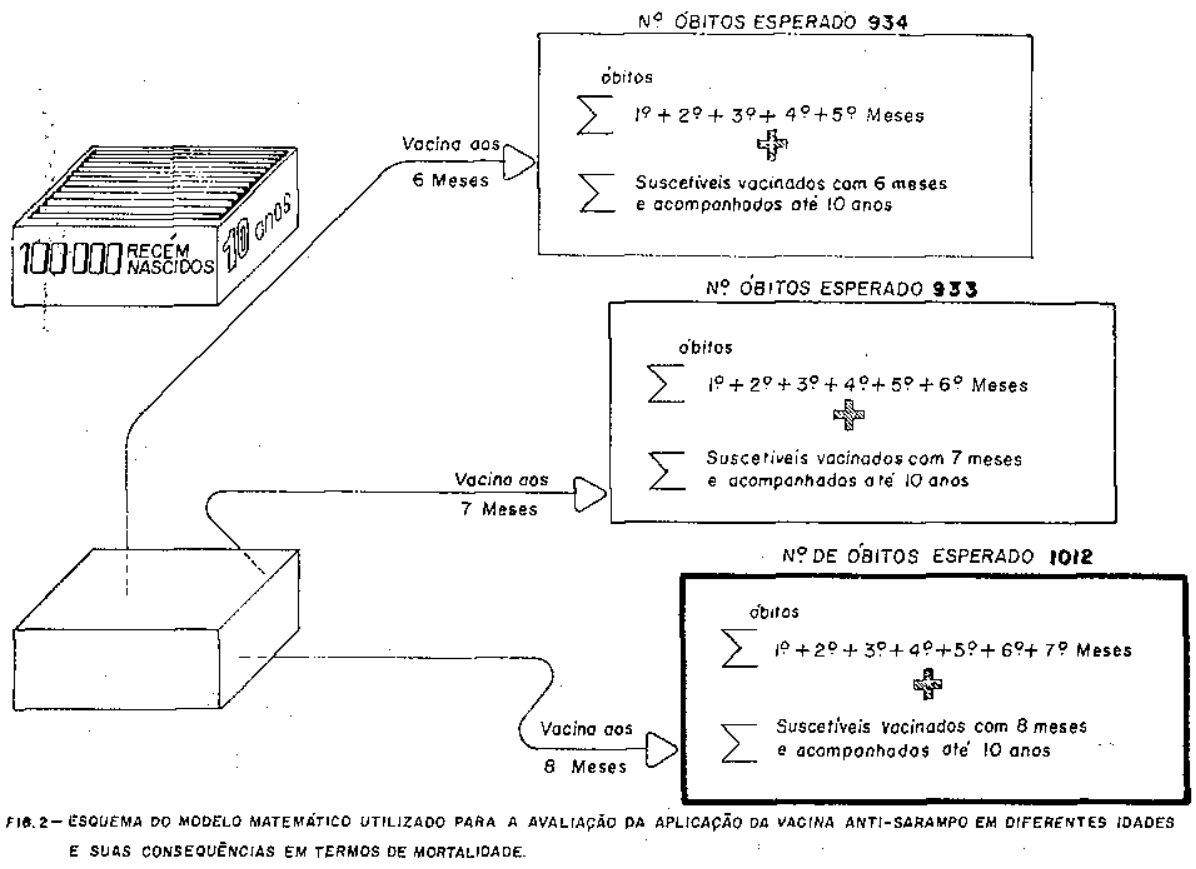


MALUF, E. M. C. P.; RIBEIRO, R. C.; RODRIGUEZ, M. A. L.; SKRABA, I. \& CARVALHO, J. F. de - Induição de anttcorpos especificos pela vacina anti-sarampo. Estudo em crianças nutridas e desnutridas de 6 a 24 meses. Rev. Inst. Med. trop. São Paulo 27:353-360, 1985.

de anticorpos detectados ${ }^{13}$. Alguns Autores ${ }^{1,2}$ acreditam que títulos de anticorpos, mesmo pequenos, significam proteção contra o sarampo.

BASS \& col. 2 argumentam que a utilização do título de $1: 10$ pela técnica de inibição da hemaglutinação como limite para se considerar uma criança protegida pode acarretar uma superestimação dos suscetíveis na população estudada. Em 318 crianças estudadas, e cujos títulos de anticorpos anti-sarampo foram deternuinados pela técnica de inibição da hemaglutinação a partir da diluição 1:10, os Autores encontraram uma grande proporção de suscetiveis, e quando repetiram o teste com diluições inferiores muitas dessas crianças demonstraram presença de anticorpos 2.

Porém o significado biológico de baixos títulos de anticorpos anti-sarampo não está bem estabelecido. ALBREDHT \& col. verificaram que 23 crianças com títulos de anticorpos neu. tralizantes de 1:4 pré-vacinação responderam à vacina, sugerindo que títulos de anticorpos muito baixos, poderiam estar relacionados com anticorpos inespecíficos ou mesmo anticorpos maternos que em níveis tão baixos seriam incapazes de interferir na resposta à vacina.

Como nāo existem informações definidas sobre o título a partir do qual haveria interferência com a vacina ou proteção contra o sarampo, em nosso estudo optamos pela utilizəção da técnica de inibição da hemaglutinação na diluição $\Longrightarrow 1: 10$ para a caracterização das crianças protegidas. Embora a escolha desse título possa ser considerado por alguns Autores como subestimação da taxa de protegidos, acreditamos que ofereceria a indicação de uma imunidade sólida e duradoura.

Observamos que a idade de aplicação da vacina foi a variável que influenciou em nossos resultados. Houve aumento progressivo na taxa de soroconversão com o aumento da idade. Muitos Autores já haviam demonstrado esse fato atribuindo a baixa taxa de soroconversão em idades menores à presença de anticorpos maternos em niveis capazes de interferir com a resposta à vacina $5,8,11,15$.

Nossos resultados mostraram que a taxa dడ soroconversão nas 223 crianças vacinadas entre 6 e 24 meses foi de 57,8\%. Essa taxa di- fere dos $90-95 \%$ teoricamente esperados, quando se atribui apenas 5 a $10 \%$ à chamada "falha pi'imária" à vacina 11. Outros estudos realizados no Brasil também demonstraram que a resposta é inferior à esperada. SCHATZMAYR \& col.12, em estudo realizado no Rio de Janeiro, encontruram uma taxa de soroconversão de $78,5 \%$ om 403 crianças vacinadas entre 6 e 25 meses. A taxa de soroconversão obtida em nosso estudo foi inferior à obtida por esses Autores, fato que pode ser explicado em parte pela maior proporção de crianças com idade entre 6 e 7 meses, idade essa que está relacionada com menor resposta à vacina.

Observamos também que o estudo nutricional não influenciou na taxa de soroconversão da amostra estudada. Esses resultados concordam com os obtidos na Tanzânia 7 , onde os desnutridos apresentaram taxa de soroconversão à vacina tão boa quanto a dos nutridos.

Analisando os resultados em termos de morbi-mortalidade por sarampo resultantes do esquema de vacinação vigente no Estado que recomenda a aplicação da vacina aos 7 meses, pode se explicar a não ocorrência de redução no coeficiente de incidência da doença pela baixa eficácia da vacina quando aplicada em crianças desse grupo etário.

Entretanto, quando analisamos a taxa de mortalidade, observamos nitidamente que essa diminuiu nos últimos anos (Fig. 1), fato que pode estar refletindo a proteção conferida pela vacina, embora num grupo pequeno, naquela idade em que a letalidade pela doença é mais ajta.

A análise dos nossos resultados sugere al. ternativas para o esquema de vacinação, haja vista a necessidade de sua reestruturação. Uma delas seria a de se vacinar aos 7 meses e desse modo influenciar na taxa de mortalidade, e revacinar após os 12 meses para se obter uma maior taxa de soroconversão.

Considerando a taxa de soroconversão obtida em nosso estudo com a revacinação, que foi de $62,96 \%$, se as 94 crianças que permaneceram soronegativas com uma dose da vacina aplicada antes dos 12 meses tivessem retornado para receber a 2." dose, o número de crianças protegidas aumentaria teoricamente de 129 pa- 
MALUF, E. M. C, P; RIBEIRO, R. C.; RODRIGUEZ, M. A. L.; SKRABA, I. \& CARVALHO, J. F. de - Inđução de anti. corpos específicos pela vacina anti-sarampo. Estudo em crianças nutridas e desnutridas de.6 a 24 meses. Rev. Inst. Med. trop. São Paulo 27:353-360, 1985.

ra 188, ou seja, a taxa de soroconversão passaria de $57,8 \%$ para $84,3 \%$.

O problema dessa proposta está relacionado com dificuldades operacionais, tais como o custo de uma revacinação e dificuldade de se conseguir o retorno, fato constatado em nosso estudo quando das 94 crianças chamadas para a revacinação apenas 27 retornaram.

Uma outra alternativa seria manter a aplicação da vacina aos 7 meses e a revacinação a partir dos 12 meses em política de campanha de vacinação em massa, com o objetivo de se atingir uma máxima redução de suscetíveis. A existência de uma taxa mínima de suscetiveis daria maior segurança para, posteriormente, retardar-se a idade de realização da vacina e considerar-se a imunização com uma única dose.

\section{CONCLUSŌES}

1) As técnicas de inibição da hemaglutinação e de soroneutralização foram comparáveis, porém a relação entre elas não foi matemati. camente bem determinada; 2) As taxas de soroconversão à vacina anti-sarampo foram inferiores às esperadas, mostrando-se compativeis com os dados de morbi-mortalidade por sarampo encontrados em nosso meio; 3) A idade de realização da vacina anti-sarampo influenciou na taxa de soroconversão obtida. Houve um aumento progressivo na porcentagem de respondedores na medida em que a idade aumentou, fato que sugere a persistência de anticorpos maternos em niveis capazes de interferir na resposta à vacina; 4) $\mathrm{O}$ sexo e o estado nutricional não influenciaram ra taxa de soroconversão obtida. As taxas de soroconversão observadas nos desnutridos marasmáticos não foram significativamente diferente das taxas registradas nas crianças nutridas; 5) A taxa de soroconversão esperada para as crianças revacinadas foi de $84,3 \%$ enquanto que para as crianças vacinadas pela primeira vez acima de 12 meses foi de $77,7 \%$. Essa diferença não foi estatisticamente significativa, portanto, não houve concordância com os dados de literatura que apontam que a vacinação em idade precoce interfere na resposta à revacinação após o primeiro ano; 6) Considerando os dados de mortalidade específicos por idade fornecidos pelo Ministério da Saúde e nossos da. dos relacionados às taxas de soroconversão, inferimos que a idade de realização da vacina pode influenciar nas taxas de mortalidade; 7) Considerando particularmente a mortalidade, a idade ótima para a vacinação seria aos sete meses. Entretanto, se considerarmos que grande parte dessas crianças vacinadas nessa idade fica suscetível, está demonstrada teoricamente a necessidade da revacinação a partir dos 12 meses.

\section{SUMMARY}

Measles vaccine. Induced specific antibody in normal and undernourished infants.

Two hundred and twenty tree children were studied regarding their response to the measles vaccine. The antibody response was measured by hemaglutination inhibition technique. Among the variables studied only the children's age at the time the vaccine was done had influence on the seroconvertion. Sex and nutritional status had no influence on the seroconvertion.

A theoric model was designed to find at what age the vaccine had the best effect in preventing mortality. The age predicte was seven months.

\section{AGRADEGIMENTOS}

Ao Professor José Ferreira Carvalho, livre docente do Instituto de Ciências Matemáticas de São Carlos - U.S.P. pela idealização do modelo matemático teórico para a determinaçăo da idade ótima para a vacinação contra o sarampo. Ao Dr. Vicente Amato Neto, professor titular de Doenças Infecciosas e Parasitárias, da Faculdade de Medicina da Universidade de São Paulo e ao Dr. José Luis da Silveira Baldy, Professor titular da disciplina de Doenças Transmissiveis do Departamento de Clínica Mé. dica, do Centro de Ciências da Saúde da Universidade Estadual de Londrina, pelas sugesiões nesse trabalho.

\section{REFERENCIAS BIBLIOGRAFICAS}

1. ALBRECHT, P.; ENNIS, F. A.; SALTZMAN, E. J. \& KRUGMAN, S. - Persistence of maternal antibody in infants beyond 12 months: mechanism of measles vaccine failure. J. Pediatr. 91: 715-718, 1977. 
MatuF, E; M. C. P.; RIBEIRO, R. C.; RODRIGUiz, M. A. L.; SKRABA, I. \& CARVAI.Ho, J. F. de - Indução de anticorpos especificos pela vacina anti-sarampo. Estudo em crianças nutridas e desnutridas de 6 a 24 meses. Rev. Inst. Med. trop. São Paulo $27: 353-360$. 1985.

2. BASS, J. W.; HALSTEAD, S. B.; FISHER, G. W. PODGORE, J. K.; PEARL, W. R.; SCHYDLOWER, M.; WIEBE, R. A. \& CHING, F. M. - Booster vaccination with further live attenuated measles vaccine. J.A.M.A. 235: $31-34,1976$.

3. BLACK, F. L. - Measles. In: LENNOTTI, E. H.; SPALDING, E. H. \& TRUANT, J. P. Manual of Clinical Microbiology, 2. ${ }^{2}$ (ed.). Am. Soc. Microbiol. 1974, p. $709 \cdot 715$.

4. CARTER, C. H.; CONWAY, T. J.; CORNFELD, D., IEZZONI, D. G.; KEMPE, C. H.; MOSCOVICI, C.; RAUH, L. W.; VIGNEC, A. J.; WARREN, J. \& HAUTE, T. - Serologic response of children to inativated measles vaccine. J.A.M.A. 179: 108-113, 1962.

5. CONFUSION and clarification of current recommenda. tions for meales vaccination. J. Pediatr. 91: 846.847, 1977.

6. CUTCHINS, E. C. - - A comparison of the hemagglutination-inhibition, neutralization and complement fixation tests in the assay of antibody to measles. J. Immunol, 88: 788-795, 1932

7. EXPANDED Programme on Immunization. Seroconver. síon after measles immunization. Wkly. Epidem. Rec. 30-31: 234-237, 1981 .

8. FULGINITI, V、A. - Immunizations: current controversies. J. Pediatr. 101: 487-494, 1982

9. HORSTMANN, D. M. - Need for monitoring vaccinated population for immunity levels. Progr. Med. Vi. rol. 16: $215-240,1973$.
10. McLAREN, D. S.; PELLlET, P. L. \& READ, W. W C. - A simple scoring system for classifiyng the severe forms of protein calorie malnutrition of early childhood. Lancet 1: 533.553, 1967.

11. RECOMMENDATION of the Immunization Practice Advisory Committe (ACIP), Measles prevention. M.M.W.R. 31: 217-231, 1982.

12. SCHATZMAYR, H. G.; NOGUEIRA, R. M. R.; BERMUDEZ, J. A. Z.; PINHĂO, A. T.; QUEIROZ, B.; VENÂNCIO, L. R.; ASSIS, C. E. R. \& SHIRAIVA, T. - Serological. response to measle vaccine (Schwarz strain) in a low-income population at Rio de Janeiro. Rev. Microbiol. 13: 242-243, 1982.

13. VERONESI, R.; SCHMID, A. W.; MOURA, R. A.; CARVALHO, R. P. S.; ZUCCAS, W. A. \& CAMARGO, M. - Revisão de dados da epidemiologia e etiologia do sarampo e subsidios para a vacinaçăo contra a doença. Arq. Fac. Híg. (S. Paulo) 17: 135-204, 2963.

14. VIAN, Y. \& PORSCH, L. M. - Programa Nacional de Vacinação: resultados observados no ano de 1982. Bol. Epidemiol. da Secretaria de Estado da Saúde e BemEstar Social do Paraná, n.o 22, 1983.

15. YEAGER, A. S.; HARVEY, B.; CROSSON, F. J.; DA. VIS, J. H.; ROSS, I. A. \& HALONEN, P. E. -- Need for measles revaccination in adolescents: correlation with birth date prior to 1972. J. Pediatr. 102: 191.195, 1983.

Recebido para publicação em 13/7/1984. 